\title{
Interactive comment on "Interacting effects of vegetation components and water table on methane dynamics in a boreal fen" by Terhi Riutta
} et al.

\section{Tariq Munir (Referee)}

tmmunir@ucalgary.ca

Received and published: 24 October 2019

\section{General comments}

Evaluation of the Interactive effects of plant functional groups and water table on $\mathrm{CH} 4$ fluxes in a boreal fen is exciting research and could confirm our understanding of the controls on $\mathrm{CH} 4$ fluxes in fen peatlands. Similar assessment studies have been conducted after the study years of 2001-2004. One of the strengths of research is that the emissions are partitioned based on vegetation components. This manuscript is concise and written very well with clarity and supports most of the earlier and later similar studies in the discussion section. The introduction covers relevant literature

Printer-friendly version

Discussion paper 
and provides clear objectives that are achieved in results and aligned with conclusions. The paper merits publication once improved as per comments. The study results confirm many reported findings that water table level is the dominant control on $\mathrm{CH} 4$ fluxes, with vegetation components affect fluxes only under natural (or higher) water table level conditions. On the other hand, authors conclude that results are relevant for evaluating peatland $\mathrm{CH} 4$ flux responses to changing climatic conditions. I believe the authors could interpret the study conclusions carefully. To my analysis, these results are relevant for fen peatland (higher water table level) $\mathrm{CH} 4$ fluxes only. The results may not be applicable to bog peatland where water table level (in most cases) is deeper than Lakkasuo study fen (natural site) where mean $\mathrm{CH} 4$ fluxes decreased to zero $(0.03 \pm$ $0.03 \mathrm{CH} 4 \mathrm{~m}-2$ month-1) after water table drawdown; Therefore authors may project the results relevancy to fen peatlands responding to changing climatic conditions. I notice that authors missed a significant opportunity of developing the $\mathrm{CH} 4$ emission factor for upscaling emissions for similar fen peatlands. The emission factors could be beneficial in reporting national or IPCC level $\mathrm{CH} 4$ emissions. Authors could look at Alm et al. 2007, Couwenberg and Fritz 2012, Levy et al. 2012 (GCB), Wilson et al. 2016, Strack et al. 2017 and few peatland $\mathrm{CH} 4$ studies from Western Canada. Study sites - Was the study site divided into two (wet or natural, and drier or WLD) in 2001 or 2002? It is given how far apart (radially) the two sites were, specifically, how far was the ditch from the wet site? Additionally, being the peatland complex (eccentric), did the authors verified if the two sites were similar in water table level and vegetation composition? These types of field investigations require additional (necessary) work so that the results obtained are solid. Was the ditch draining to some larger ditch/drain? Authors need to extend and clarify on sites, their chemistry and manipulation It would be methodologically challenging to create secluded vegetation removal treatments even after using paraffin wax, for example: âĂć In PS, sedge stubbles/roots could still mediate fluxes âÁć I believe that removal leaves underground roots/rhizomes, a large amount of substrate, which could result in undesirable data The authors need to explain how these problems were resolved. Based on earlier findings (for example, Conrad 2009, Han-

Printer-friendly version

Discussion paper
Interactive comment 
son et al. 2000), they could support their removal treatments with several justifications - Lignin or associated polysaccharides are not but simpler carbohydrates or photosynthates are the dominant substrates. Clipping or removal disrupts the photosynthates movement to roots, which may not support dominant substrate-dependent $\mathrm{CH} 4$ production. ................ The explanations could also help discuss the water level $\times$ vegetation component interaction for $\mathrm{CH} 4$ fluxes The underlying mechanisms of $\mathrm{CH} 4$ production/release are established; however, authors need to briefly mention in the discussion to help the reader learn or refresh their understanding. The authors need to add some discussion (or sub-heading) on the water table level - vegetation interaction.

Specific comments

Line 13. The hyphen used here is inappropriate and could be replaced with a comma Line 14. Which growing seasons? Line 15. Insert "each of" after "of" I notice the use of super- or sub-scripts is inconsistent. Also, acronyms are not described in their first instances What could be the reasons the shrubs component attenuated the fluxes? References could be used for discussing ideas Line 22. What authors mean high here? Better say natural. Alternately, give how high? Line 23. Change "in" with "to" Line 24. Drawdown is a general term when mentioning climate change impacts; could be replaced with "deepening" Line 77 . How the Lakkasuo peatland complex is an eccentric raised bog - a brief explanation would be helpful for the reader to understand how a nutrient-poor, oligotrophic fen existed within a bog. Line 81-87. Any visual/coverage estimates (numbers)? Line 100. I notice the use of spacing between a digit and a sign (- or + ) is not consistent throughout the manuscript Line 102. Additional dot Line 110. Length $\times$ Width Line 124. Water table level Line 129. Any reference for species-specific Gaussian curves? Line 153-154. I notice authors tested here $\mathrm{WL}$ and Veg differences and provide results later in the results section) Line 238-241. Interesting to note that this study (2001-2004) compares results with earlier as well as later studies Figure 3. Add significance letters

Printer-friendly version

Discussion paper 
Please also note the supplement to this comment:

https://www.biogeosciences-discuss.net/bg-2019-350/bg-2019-350-RC1-

supplement.pdf

Interactive comment on Biogeosciences Discuss., https://doi.org/10.5194/bg-2019-350, 2019. 